\title{
SODIUM VALPROATE VERSUS FOSPHENYTOIN FOR STATUS EPILEPTICUS IN CHILDREN- A RANDOMIZED CONTROL TRIAL
}

\author{
Rajasekar $S^{1}$, Selvakumar P2, Mohamed Nazar R ${ }^{3}$
}

1 Professor, Department of Paediatrics, Thanjavur Medical College, Thanjavur, Tamilnadu, India.

${ }^{2}$ Associate Professor, Department of Paediatrics, Thanjavur Medical College, Thanjavur, Tamilnadu, India.

3Junior Resident, Department of Paediatrics, Thanjavur Medical College, Thanjavur, Tamilnadu, India.

\begin{abstract}
BACKGROUND

Status epilepticus (SE) is a life-threatening neurological emergency in children associated with high morbidity and mortality. Phenytoin/fosphenytoin is the currently recommended first choice second line treatment in children, although there is lack of evidence for its use and it is associated with significant side effects. Emerging evidence suggests that intravenous (IV) sodium valproate may be more effective with fewer side effects. The objective of this study was to compare the efficacy and safety of IV sodium valproate with IV fosphenytoin as a second line treatment for SE in Indian children.
\end{abstract}

\section{METHODS}

This is a prospective randomized control trial conducted in the department of paediatric emergency of Raja Mirasudar Hospital attached to Thanjavur Medical College, Thanjavur, South India, from October 2017 to July 2018 among 30 children aged 2 years to 12 years admitted for SE, and in whom seizure did not terminate even with 2 doses of benzodiazepines. 20 mg Phenytoin equivalent (PE)/kg of fosphenytoin (FPHT) over 7 minutes or $20 \mathrm{mg} / \mathrm{kg}$ of sodium valproate (SVP) over 5 minutes. Clinical cessation of seizures five minutes following the completion of the infusion of the study medication was the expected primary outcome.

\section{RESULTS}

Sodium valproate terminated seizures earlier than fosphenytoin $(\mathrm{P}=0.001)$. There was no significant difference between the two drugs with respect to recurrence of seizures within 24 hours ( $p>0.999)$. The adverse events did not differ significantly between the two groups $(\mathrm{p}=0.715)$.

\section{CONCLUSIONS}

Sodium valproate may be an effective alternative to fosphenytoin in the management of SE in children.

HOW TO CITE THIS ARTICLE: Rajasekar S, Selvakumar P, Mohamed Nazar R. Sodium valproate versus fosphenytoin for status epilepticus in children- a randomized control trial. J. Evolution Med. Dent. Sci. 2019;8(18):1474-1478, DOI: $10.14260 /$ jemds/2019/328

\section{BACKGROUND}

Status epilepticus (SE) is a serious, life-threatening neurological pediatric emergency characterized by prolonged seizure activity.[1] Approximately 4.5 million cases of SE occur worldwide in pediatric age group. Mortality from refractory SE is $20 \%-30 \%$ and over $50 \%$ survivors have neurological sequelae.[2] It has an annual incidence of 17-23 cases/100000 children per year.[3] Immediate treatment of status epilepticus is essential to prevent neurological sequelae which occurs in up to $39 \%$ of children and mortality which is reported at $\left.3-5 \% .{ }^{4}\right]$

Status epilepticus is most widely defined as a seizure lasting more than 30 minutes or recurrent seizures more than 30 minutes during which the patient does not regain consciousness. ${ }^{[5,6]}$

An operational definition of SE suggested for adults and children older than 5 years by Lowenstein DH et al., refers to

'Financial or Other Competing Interest': None.

Submission 14-03-2019, Peer Review 19-04-2019,

Acceptance 26-04-2019, Published 06-05-2019.

Corresponding Author:

Dr. Selvakumar $P$,

\#180, $9^{\text {th }}$ Cross,

Arulanandha Nagar Extension,

Thanjavur-613001,

Tamilnadu, India.

E-mail: drselva_kumar69@yahoo.co.in

DOI: $10.14260 /$ jemds $/ 2019 / 328$

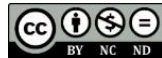

more than 5 minutes of continuous seizures or two or more discrete seizures between which there is incomplete recovery of consciousness. [7]

Benzodiazepines are the preferred class of medication for the initial treatment of status epilepticus. ${ }^{[8]}$ Historically lorazepam has been the preferred benzodiazepines for emergent medical therapy of status epilepticus. Recent data support the use of diazepam and midazolam in addition to lorazepam for seizures in paediatric status epilepticus.

Because of the unfavourable side effects phenytoin has been relegated to second line treatment following inadequate response or contraindication to benzodiazepines. Fosphenytoin (FPHT), prodrug of phenytoin is preferred in children in view of its lower potential for local tissue and cardiac toxicity. [9]

Sodium valproate is effective and safe in the treatment of SE and is not associated with serious side effects. The drug is cheap and easily available and is being increasingly used in therapeutic protocol, but its efficacy in SE is to be formally characterized.[10] Keeping in view of the above facts, the study was planned to see the safety and efficacy of intravenous sodium valproate in comparison to intravenous fosphenytoin in children with SE. 


\section{METHODS}

\section{Place of Study}

Raja Mirasudar Hospital attached to Thanjavur Medical College, Thanjavur, South India.

\section{Period of Study}

October 2017 to July 2018.

\section{Study Design}

Prospective Randomized Control Trial.

\section{Case Allocation}

Cases were allocated randomly between the groups by random sequence generator using open epi.com.

\section{Sample Size}

Sample size for our study was calculated using open epi.com, keeping the type error $(\alpha)$ as 0.95 , power $(\beta)$ as 0.8 , ratio of sample as 1 and mean difference $(\sigma)$ of seizure control time in seconds as 0.8 and the standard deviation of the same between the groups as 0.08 the sample size required for each group was 15. Hence for two groups the sample required was 30 .

\section{Inclusion Criteria}

30 children aged between 2 years and 12 years who presented to paediatric emergency department with convulsive status epilepticus and who were still seizing after two doses of benzodiazepines (Diazepam/lorazepam/ midazolam) administered by one of the following route (Rectal/buccal/intranasal/intravenous/intramuscular) at the recommended dose were included in the study.

SE is defined as a child who was unresponsive with continuing abnormality of movement (increased tone or jerking) of greater than five minutes duration, or two or more recurrent convulsions without recovery of consciousness between convulsions.[6]

This definition encompasses the International League against Epilepsy (ILAE) seizures types of generalized tonic clonic convulsions, secondarily generalized tonic clonic convulsions and complex partial status epilepticus but not absence, myoclonic, tonic and simple partial status epilepticus.

\section{Exclusion Criteria}

Children on regular oral phenytoin and sodium valproate use, SE due to an obvious major head injury, known contraindication or allergy to sodium valproate or fosphenytoin, administration of second line anticonvulsant (Phenytoin, fosphenytoin, phenobarbitone, sodium valproate) in the previous 24 hours, with known liver diseases, with urea cycle disorders, with cardiac complications like hypotension and cardiac arrhythmias were excluded from the study.

\section{Study Procedure}

All recruited children were randomized to receive either 20 $\mathrm{mg} / \mathrm{kg}$ of SVP infusion over 5 minutes diluted $1: 1$ with $0.9 \%$ sodium chloride to a minimum volume of $10 \mathrm{ml}$ or $20 \mathrm{mg} / \mathrm{kg}$
PE of FPHT diluted 1 in 4 with $0.9 \%$ sodium chloride to a minimum volume of $20 \mathrm{ml}$.

The primary outcome was assessed five minutes following the infusion of study medication for successful clinical cessation of seizures. Secondary outcome includes a) recurrence of seizure within 24 hours, b) drug related adverse events like death, airway complication and cardiovascular instability (cardiac arrest, arrhythmias, hypotension requiring intervention).

The participants were examined for the following: 1) increased tone, 2) jerking movements including nystagmatoid eye movement 3) level of consciousness according to Alert, Voice, Pain, Unresponsive (AVPU) Scale. Continued seizure activity was defined as the presence of increased tone or jerking movements. If seizure activity ceases, then the time is recorded. If the seizure activity was present after 5 minutes following infusion of medication, then alternate medications as per hospital treatment protocol was administered.

\section{Statistical Analysis}

Differences were assessed using Mann-Whitney U test, Fischer's exact test and unpaired ' $\mathrm{t}$ ' test. Data were expressed as mean \pm standard deviation values. $P$ value of $<0.05$ was considered to be significant. The study was approved by the Institutional Ethical Committee. Written informed consent was obtained from the parents.

\section{RESULTS}

A total of 42 children presented with status epilepticus during the study period. Of them six children who were less than 2 years, five on regular oral sodium Valproate and one with hypotension were excluded from our study. In our study, 30 children were randomized to receive either iv fosphenytoin or iv sodium valproate. There were no significant differences between the groups with regard to sex, weight, type, duration of seizure and developmental status of the children. Socio-demographic characteristics of the enlisted children are provided in table I.

Mean age in Fosphenytoin group was $5.33 \pm 3.05$ years whereas in sodium Valproate group, it was $3.31 \pm 1.44$ years which was statistically significant $(' p '=0.031)$. Although it was statistically significant it does not affect our study because dosage of administered drug in our study is based on weight of the child and not the age.

The etiology of seizures in the study group with decreasing order of frequency based on clinical findings were acute symptomatic (Acute CNS infection, hypertension) and febrile status epilepticus. The etiological profile of the study population is shown in table II.

Following treatment 9 children developed adverse drug reaction in fosphenytoin group, whereas 7 had adverse reaction in sodium Valproate group. The ' $p$ ' value was not significant $(\mathrm{p}=0.715)$. Ataxia, vomiting, respiratory distress and hypotension were noted in fosphenytoin group, whereas abdominal pain and somnolence were noted in sodium Valproate group. 


\begin{tabular}{|c|c|c|c|}
\hline Variable & FPHT $(n=15)$ & SVP (n=15) & p Value \\
\hline Age & $\begin{array}{l}5.33 \pm 3.05 \\
(4.5 ;(2.5-8)\end{array}$ & $\begin{array}{c}3.31 \pm 1.44 \\
(3 ;(2.5-4)\end{array}$ & $0.031^{*}$ \\
\hline \multicolumn{4}{|c|}{ Gender } \\
\hline Male & $7(46.7 \%)$ & $9(60 \%)$ & 0.499 \\
\hline Female & $8(53.3 \%)$ & $6(40 \%)$ & \\
\hline Weight & $\begin{array}{l}16.46+6.86 \\
(13 ;(12-23)\end{array}$ & $\begin{array}{c}13.2+2.33 \\
(13 ;(11.5-15)\end{array}$ & 0.102 \\
\hline Past history of seizures & $3(20 \%)$ & $5(33.3 \%)$ & 0.341 \\
\hline \multicolumn{4}{|c|}{ Type of Seizure } \\
\hline Focal seizure & $5(33.3 \%)$ & $2(13.3 \%)$ & 0.195 \\
\hline GTCS & $10(66.7 \%)$ & $13(86.7 \%)$ & \\
\hline \multicolumn{4}{|c|}{ Development Status } \\
\hline Abnormal & $2(13.3 \%)$ & $3(20 \%)$ & 0.499 \\
\hline Normal & $13(86.7 \%)$ & $12(80 \%)$ & \\
\hline Duration of seizures & $\begin{array}{l}16.66 \pm 9.57 \\
(15 ;(10-30)\end{array}$ & $\begin{array}{l}15.66 \pm 6.51 \\
(15 ;(10-15)\end{array}$ & 0.740 \\
\hline
\end{tabular}

Table I. Socio-Demographic and Seizure Characteristics $(N=30)$

*indicates $\mathrm{p}$ value $<0.05$ and considered as statistically significant. Mann Whitney U test was used to test the significance. Data are expressed as n (\%) except age, weight and duration of seizures (median; IQR)

\begin{tabular}{|c|c|c|}
\hline Aetiology & FPHT (n=15) & $\operatorname{SVP}(n=15)$ \\
\hline Acute CNS infection & $6(40 \%)$ & $2(13.3 \%)$ \\
\hline Febrile status epilepticus & $3(20 \%)$ & $5(33.3 \%)$ \\
\hline New onset seizure disorder & $3(20 \%)$ & $4(26.7 \%)$ \\
\hline Seizure disorder (Break through seizures) & $1(6.7 \%)$ & $4(26.7 \%)$ \\
\hline Hypertensive encephalopathy & $1(6.7 \%)$ & - \\
\hline Seizure disorder (Noncompliance) & $1(6.7 \%)$ & - \\
\hline
\end{tabular}

\section{Table II. Etiological Profile in Enrolled Children $(\mathrm{N}=30)$}

The study outcomes are shown in table III. Sodium valproate ( $2.38 \pm 0.55$ minutes) terminated seizure earlier than fosphenytoin (3.32 \pm 0.84 minutes) $\mathrm{P}=0.029$, which was statistically significant.

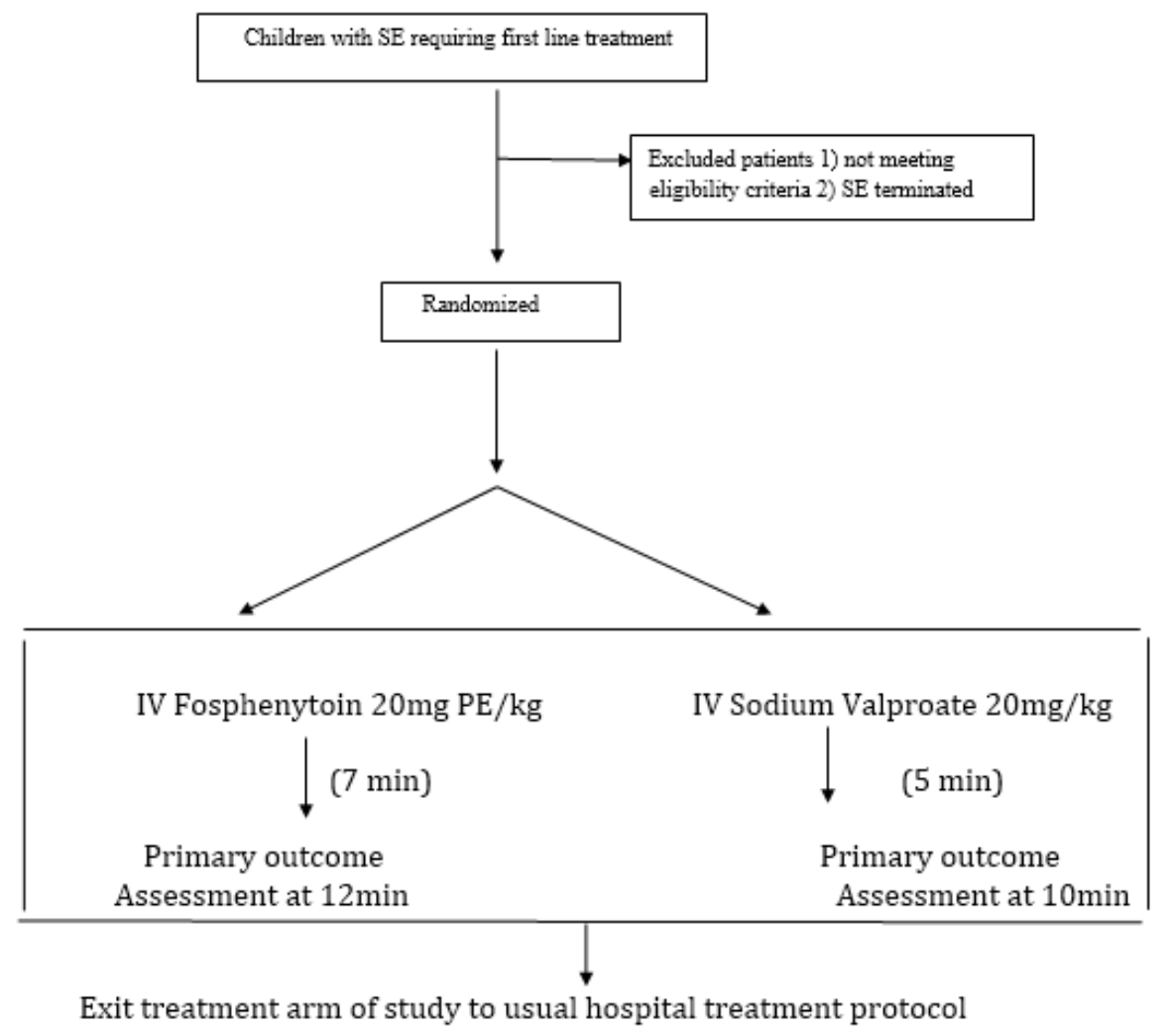

Figure 1. Study Protocol 


\begin{tabular}{|c|c|c|c|c|}
\hline Variable & FPHT Group & SVP Group & p Value & Statistical Test \\
\hline $\begin{array}{c}\text { Time taken to terminate seizures } \\
\text { (minutes) }\end{array}$ & $3.32 \pm 0.84$ & $2.38 \pm 0.55$ & $0.001^{*}$ & Unpaired “ $\mathrm{t}$ " test \\
\hline $\begin{array}{c}\text { Recurrence of seizures } \\
\text { Adverse effects }\end{array}$ & $6.7 \%$ & $6.7 \%$ & $>0.999$ & Fischer's exact test \\
\hline
\end{tabular}

Table III. Primary and Secondary Outcome Variable of The Study Groups

*indicates $\mathrm{p}$ value $<0.05$ and considered as statistically significant.

\begin{tabular}{|c|c|c|c|c|}
\hline Sl. No. & Study & Phenytoin /Fosphenytoin & Sodium Valproate & 'p' Value \\
\hline 1 & Our study & 93.3 (Fosphenytoin) & $93.3 \%$ & Not significant \\
\hline 2 & Zeid Yasiry et al[11] & $50.2 \%$ (Phenytoin) & $75.7 \%$ & - \\
\hline 3 & $\begin{array}{c}\text { Misra UK } \\
\text { et al[12] }\end{array}$ & $42 \%$ (Phenytoin) & $60 \%$ & Not significant \\
\hline
\end{tabular}

Table IV. Comparison with Other Studies with Regard to Seizure Cessation Rate

\section{DISCUSSION}

The study was done during a period of 7 months from January -July 2018. There was a total of 42 children who presented with status epilepticus during this period of which, 30 children fulfilled the inclusion criteria. Among those 30 children, 15 of them were treated with fosphenytoin and the remaining with sodium valproate. In this study, we compared fosphenytoin with sodium valproate in terms of their effectiveness (both efficacy and adverse drug reactions) in benzodiazepine resistant status epilepticus.

In the study Group I (Fosphenytoin group), $46.7 \%$ were male children. The mean age was 5.33 years; with a mean weight of $16.46 \mathrm{~kg}$ and mean seizure duration of 16.66 minutes. Previous AED intake was found in 3 cases and delayed developmental milestones in $13.3 \%$. In the study Group II (sodium valproate group), $60 \%$ were male children. The mean age was 2.28 years; with a mean weight of $13.2 \mathrm{~kg}$ and mean seizure duration of 15.66 minutes. Previous AED intake was found in 5 cases and delayed developmental milestones in $20 \%$.

The most common type of seizure was GTCS followed by focal seizures. None had myoclonic seizures. In our study, seizure cessation rate following both fosphenytoin and sodium valproate administration was $93.3 \%$. In a previous study done by Zeid Yasiry et al, the efficacy of sodium valproate was $75.7 \%$ and phenytoin was $50.2 \%$.[11] In their study, 798 cases of convulsive SE were analysed retrospectively. The study by Misra UK et al revealed that seizure cessation rate for Valproate as $60 \%$ and for phenytoin as $42 \%$ which was statistically insignificant as in our study.[12] There is no previous data comparing fosphenytoin with sodium valproate in children.

In our study sodium valproate terminated seizures earlier than fosphenytoin. The mean time taken to terminate seizures was $3.32 \pm 0.84$ minutes in fosphenytoin group whereas it was $2.38 \pm 0.556$ minutes for sodium valproate. In a study by Somsak Tiamkao et al. time taken to control seizure was less in sodium valproate group compared to phenytoin group $(\mathrm{p}=0.173),[13]$ which is comparable to our study, but their study was done in children $>15$ years. In both the study groups the recurrence rate was $6.7 \%(1 / 15)$, which is similar to the results of a previous study done by Puneet Agarwal et al.[14]
In a study done by Kian-Ti Yu et al. it was concluded that intravenous valproate loading was safe and effective for treating acute seizure emergencies in children.[15] In our study also the adverse effects are less in sodium valproate group when compared to fosphenytoin group. According to Leppik and his colleagues, serious cardiovascular and respiratory adverse reactions were not observed during IV infusion of FPHT.[16] In our study, hypotension was noted in 1 case. In Ramsay RE and Wilder BJ et al study, $67 \%$ of patient receiving parenteral phenytoin experienced transient CNS side effects like nystagmus, ataxia and dizziness but no patient developed intolerance to fosphenytoin.[17] In our study, ataxia was noted in 2 children $(13.3 \%)$ treated with fosphenytoin, who recovered on switching to oral antiepileptic drugs.

\section{Limitation}

The limitation of this study was the relatively small sample size. There may have been a bias in the subject inclusion or the analysis of seizure control as the study was done in a single institution. The therapeutic end point of any antiepileptic drug would be cessation of all electrical seizures but in our study the primary outcome did not include electroencephalography (EEG) for confirmation of seizure termination.

\section{CONCLUSIONS}

Sodium valproate may be an effective alternative to fosphenytoin as a second line drug in the management of status epilepticus in children. However, we need further clinical studies with large sample size to further define the efficacy of sodium valproate in SE in paediatric population.

\section{REFERENCES}

[1] Shinnar S, Pellock JM, Moshe SL, et al. In whom does status epilepticus occur: age-related differences in children. Epilepsia 1997;38(8):907-14.

[2] DeLorenzo RJ. Epidemiology and clinical presentation of status epilepticus. Adv Neurol 2006;97:199-215.

[3] Chin RF, Neville BG, Peckham C, et al. Incidence, cause, and short-term outcome of convulsive status 
epilepticus in childhood: prospective populationbased study. Lancet 2006;368(9531):222-9.

[4] Raspall-Chaure M, Chin RF, Neville BG, et al. Outcome of paediatric convulsive status epilepticus: a systematic review. Lancet Neurol 2006;5(9):769-79.

[5] Treatment of convulsive status epilepticus. Recommendations of the Epilepsy Foundation of America's Working Group on Status Epilepticus. JAMA 1993;270(7):854-9.

[6] Guidelines for epidemiologic studies on epilepsy. Commission on epidemiology and prognosis, International league against epilepsy. Epilepsia 1993;34(4):592-6.

[7] Lowenstein DH, Bleck T, Macdonald RL. It's time to revise the definition of status epilepticus. Epilepsia 1999;40(1):120-2.

[8] Appleton R, Macleod S, Martland T. Drug management for acute tonic-clonic convulsions including convulsive status epilepticus in children. Cochrane Database Syst Rev 2008;(3):CD001905.

[9] Glauser T, Shinnar S, Gloss D, et al. Evidence-based guideline: treatment of convulsive status epilepticus in children and adults: report of the guideline committee of the American epilepsy society. Epilepsy Curr 2016;16(1):48-61.

[10] Ramsay RE, Cantrell D, Collins SD, et al. Safety and tolerance of rapidly infused Depacon. A randomized trial in subjects with epilepsy. Epilepsy Res 2003;52(3):189-201.
[11] Yasiry Z, Shorvon SD. The relative effectiveness of five anti-epileptics in treatment of benzodiazepine resistant convulsive status epilepticus: a meta-analysis of published studies. Seizure 2014;23(3):167-74.

[12] Misra UK, Kalita J, Patel R. Sodium valproate vs phenytoin in status epilepticus; a pilot study. Neurology 2006;67(2):340-2.

[13] Tiamkao S, Sawanyawisuth K, Chancharoen A. The efficacy of intravenous sodium valproate and intravenous phenytoin as the first line treatment in status epilepticus: a comparison study. BMC Neurol 2013;13:98.

[14] Agarwal P, Kumar N, Chandra R, et al. Randomized study of intravenous valproate and phenytoin in status epilepticus. Seizure 2007;16(6):527-32.

[15] Yu KT, Mills S, Thompson N, et al. Safety and efficacy of intravenous valproate in pediatric status epilepticus and acute repetitive seizures. Epilepsia 2003;44(5):724-6.

[16] Leppik IE, Boucher R, Wilder BJ, et al. Phenytoin prodrug: preclinical and clinical studies. Epilepsia 1989;30 Suppl 2:S22-6.

[17] Ramsay RE, Wilder BJ, Uthman BM, et al. Intramuscular fosphenytoin (Cerebyx) in patients requiring loading dose of phenytoin. Epilepsy Res 1997;28(3);181-7. 